\title{
Complement regulator CD59 prevents peripheral organ injury in rats made seropositive for neuromyelitis optica immunoglobulin $\mathrm{G}$
}

\author{
Xiaoming Yao and Alan S. Verkman*
}

\begin{abstract}
Pathogenesis in aquaporin-4 immunoglobulin G (AQP4-lgG) seropositive neuromyelitis optica spectrum disorders (herein called NMO) involves complement-dependent cytotoxicity initiated by AQP4-lgG binding to astrocyte AQP4. We recently reported that rats lacking complement inhibitor protein CD59 were highly susceptible to development of NMO pathology in brain and spinal cord following direct AQP4-IgG administration (Yao and Verkman, Acta Neuropath Commun 2017, 5:15). Here, we report evidence that CD59 is responsible for protection of peripheral, AQP4-expressing tissues in seropositive NMO. Rats made seropositive by intraperitoneal injection of AQP4-lgG developed marked weakness by $24 \mathrm{~h}$ and died soon thereafter. Serum creatine phosphokinase at $24 \mathrm{~h}$ was $>900$-fold greater in seropositive $\mathrm{CD} 59^{-/-}$rats than in seropositive $\mathrm{CD} 59^{+/+}$(or control) rats. AQP4-expressing cells in skeletal muscle and kidney, but not in stomach, of seropositive $\mathrm{CD} 59^{-/-}$rats showed injury with deposition of AQP4-IgG and activated complement C5b-9, and inflammation. Organ injury in seropositive CD59 ${ }^{-1-}$ rats was prevented by a complement inhibitor. Significant pathological changes in seropositive $\mathrm{CD}_{59^{-/}}$rats were not seen in optic nerve, spinal cord or brain, including circumventricular tissue. These results implicate a major protective role of CD59 outside of the central nervous system in seropositive NMO, and hence offer an explanation as to why peripheral, AQP4-expressing cells are largely unaffected in NMO.
\end{abstract}

Keywords: NMO, Aquaporin-4, Complement inhibitor, Skeletal muscle, Kidney, Astrocyte, Transgenic rat

\section{Introduction}

Complement-mediated cytotoxicity plays a central role in the pathogenesis of seropositive neuromyelitis optica spectrum disorders (herein called NMO), in which immunoglobulin $G$ autoantibodies against water channel aquaporin-4 (AQP4), called AQP4-IgG, bind to astrocytes in brain, spinal cord and optic nerve [9, 10]. Following astrocyte injury, downstream inflammation, blood-brain barrier disruption and potentially additional mechanisms result in oligodendrocyte injury and demyelination [11, 17, 29]. Optic neuritis and transverse myelitis are the major clinical manifestations of NMO, which can produce visual and motor impairment, and brain involvement can occur as well. Though AQP4 is expressed in

\footnotetext{
* Correspondence: Alan.Verkman@ucsf.edu; http://www.ucsf.edu/verklab Departments of Medicine and Physiology, University of California, 1246

Health Sciences East Tower, San Francisco, CA 94143-0521, USA
}

some peripheral organs outside of the central nervous system, including skeletal muscle, kidney and stomach $[8,19]$, these organs are rarely affected in NMO, with only a few reports of NMO-associated myositis associated with elevated creatine phosphokinase and skeletal muscle pathology [7, 13, 27].

It has been unclear why peripheral AQP4-expressing cells, which are exposed to high levels of circulating AQP4-IgG in seropositive NMO, are largely spared. Rodent studies show prompt deposition of circulating AQP4-IgG on peripheral AQP4-expressing cells $[1,20]$, and humans can be AQP4-IgG seropositive for many years prior to clinical manifestations of NMO [16]. Rodents administered AQP4-IgG systemically do not spontaneously develop pathological changes in the central nervous system or in peripheral organs, though pathology in 
brain is seen following mechanical disruption of the blood-brain barrier [1].

Here, we tested the hypothesis that complement regulator protein $\mathrm{CD} 59$ is responsible for protection of AQP4-expressing peripheral cells in seropositive NMO. CD59 is a phosphoinositol-linked membrane glycoprotein that inhibits formation of the complement terminal membrane attack complex $[6,21,26,34]$. The motivation for this work is the expression of CD59 in AQP4-expressing cells in the central nervous system and in the periphery, and our prior data showing that $\mathrm{CD} 59^{-/-}$mice are highly sensitive to development of NMO pathology following direct administration of AQP4-IgG and human complement into brain or cerebrospinal fluid [33]. $\mathrm{CD} 59^{-/-}$rats also develop marked brain and spinal cord pathology following direct AQP4-IgG administration [32], albeit without the need for coadministration of complement, because rats, unlike mice, have an active classical complement system $[2,22]$. We report here marked injury to skeletal muscle following systemic AQP4-IgG administration to CD59 $9^{-/-}$ rats, offering an explanation for the sparing of peripheral organs in seropositive NMO.

\section{Materials and methods Materials}

Purified recombinant AQP4-IgG (rAb-53) [3, 5] was provided by Dr. Jeffrey Bennett (Univ. Colorado, Denver) and (non-NMO) pooled human IgG, as control, was purchased from Pierce Biotechnology (Rockford, IL). Some studies were done using an antibody fragmentbased complement inhibitor, herein called Comp inh (to be reported separately), which inhibits serum complement activity by $>95 \%$ for $8-12 \mathrm{~h}$ after intravenous administration. Unless otherwise specified chemicals were purchased from Sigma-Aldrich (St. Louis, MO).

$\mathrm{CD} 59^{-/-}$rats

$\mathrm{CD} 59^{-/-}$rats in a Sprague-Dawley background were custom-generated by Transposagen Biopharm. Inc. (Lexingtobon, KY) using CRISPR-Cas9 gene targeting technology as described [32]. In vivo studies were done on 8 - to 10 -week-old, weight-matched CD59+/+ and $\mathrm{CD} 59^{-/-}$rats. Rats were maintained in air-filtered cages and fed normal rat chow in the University of California, San Francisco (UCSF) Animal Care facility. All procedures were approved by the UCSF Committee on Animal Research (approval number AN108551).

\section{Blood and urine analysis}

Blood $(800 \mu \mathrm{L})$ was collected before and $24 \mathrm{~h}$ after AQP4-IgG injection. Hematological parameters were measured using a Genesis Hematology Analyzer (Oxford Science, Oxford, CT) in which $80 \mu \mathrm{L}$ blood was collected into a MiniCollect tube with EDTA (Greiner Bio-One $\mathrm{GmbH}$, Kremsmunster, Austria). Serum was obtained by collection of blood in 1.5-ml Eppendoff tubes then allowing clotting for $30 \mathrm{~min}$ followed by centrifugation at $800 \mathrm{~g}$ for $10 \mathrm{~min}$ at $4{ }^{\circ} \mathrm{C}$. Serum was frozen at $-70^{\circ}$ $\mathrm{C}$ for blood chemistry analyses (IDEXX BioResearch, Sacramento, CA). Urine was collected for determination of osmolality using a freezing-point depression osmometer (Model 3320 Osmometer, Advanced Instruments Inc., Natick, MA).

\section{AQP4-IgG pharmacokinetics}

Adult $\mathrm{CD} 59^{+/+}$and $\mathrm{CD} 59^{-/-}$rats were administered AQP4-IgG ( $4 \mathrm{mg} / \mathrm{kg}$ body weight in PBS) by intraperitoneal injection in a total volume of $500 \mu \mathrm{L}$. Blood was collected through the tail vein at $1,2,4,6,8,24$ and $48 \mathrm{~h}$, left for $30 \mathrm{~min}$ at room temperature to allow clotting, and centrifuged for $10 \mathrm{~min}$ at $800 \mathrm{~g}$ at $4{ }^{\circ} \mathrm{C}$. Serum was diluted 50,000-fold and human IgG concentration was determined using a human IgG ELISA kit (GenWay, San Diego, CA).

\section{Intraperitoneal injection model}

AQP4-IgG or (non-NMO) control human IgG $(5 \mathrm{mg} / \mathrm{kg}$ body weight) was injected intraperitoneally. At $24 \mathrm{~h}$, clinical motor scores were recorded, as adapted from scoring used for neuroinflammation models in rodents [18]: score 0 , normal movement; score 1, tail paralysis; score 2, hindlimb paralysis; score 3 , hindlimb and frontlimb paresis with breathing difficulty; score 4, complete paralysis with moribund condition. Then rats were deeply anesthetized using ketamine $(100 \mathrm{mg} / \mathrm{kg})$ and xylazine $(10 \mathrm{mg} / \mathrm{kg})$ and transcardially perfused with $200 \mathrm{~mL}$ heparinized PBS and $200 \mathrm{~mL}$ of 4\% PFA in PBS. Brain, optic nerve, spinal cord (cervical), skeletal muscle, kidney and stomach were removed and post-fixed for $4 \mathrm{~h}$ in $4 \%$ paraformaldehyde (PFA) and cryoprotected in $20 \%$ sucrose. Tissues were embedding in OCT compound and sectioned at 7- $\mu \mathrm{m}$ thickness using a cryostat (CM1900, Leica) for immunofluorescence. For complement inhibition studies, Comp inh $(50 \mathrm{mg} / \mathrm{kg})$ was injected intravenously just before and $12 \mathrm{~h}$ after intraperitoneal AQP4-IgG (or control IgG) administration.

\section{Immunofluorescence}

Frozen sections of harvested tissues were immunostained as described [32]. Briefly, sections were incubated in blocking solution (1\% BSA containing $0.3 \%$ Triton X-100 in PBS) for $1 \mathrm{~h}$ at room temperature, then incubated overnight at $4{ }^{\circ} \mathrm{C}$ with primary antibodies against AQP4 (1:200, Santa Cruz Biotechnology), human IgG (1:200, Santa Cruz Biotechnology), C5b-9 (1:100, Hycult Biotech, PA), CD45 (1:50, Cambridge, MA), CD59 and CD55 (1:50, LSBio, Seattle, WA), CD46 (1:50, Abcam, MA), GFAP 
(1:200; Millipore), ionized calcium binding adaptor molecule 1 (Iba1; 1:400, Wako, Richmond, VA), or myelin basic protein (MBP, 1:100, Santa Cruz Biotechnology), followed by the appropriate species-specific Alexa Fluorconjugated secondary antibody for $1 \mathrm{~h}(5 \mu \mathrm{g} / \mathrm{mL}$ each, Invitrogen) at room temperature. Sections were mounted with Prolong Gold antifade reagent with DAPI (Invitrogen, Life Technologies, Eugene, OR) for visualization of immunofluorescence on a Leica fluorescence microscope or Nikon confocal microscope.

\section{Statistics}

Data are presented as mean \pm S.E.M. Statistical analysis was performed using Prism 5 GraphPad Software package (San Diego, CA). The normality of the data was established by Bartlett's test for equal variances and a one-way ANOVA with Newmann-Keuls post-hoc test to compare groups.

\section{Results}

Expression of complement inhibitor proteins in AQP4-expressing organs

Immunofluorescence of AQP4 and complement inhibitor proteins in Fig. 1a shows coexpression of AQP4 and CD59 in three major peripheral tissues in which AQP4 is expressed - skeletal muscle, kidney and stomach. Staining was seen in sarcolemma in skeletal muscle, in basolateral plasma membrane in inner medullary collecting duct in kidney, and in parietal cells in glands in stomach. CD59 immunofluorescence was absent in organs from $\mathrm{CD} 59^{-/-}$ rats, and AQP4 immunofluorescence did not differ significantly in tissues from $\mathrm{CD} 59^{+/+}$and $\mathrm{CD} 59^{-/-}$rats (relative to 1.0 for $\mathrm{CD} 59^{+/+}$rats: $1.01 \pm 0.07$ (skeletal muscle); $1.04 \pm 0.07$ (kidney); $0.96 \pm 0.09$ (stomach)). Complement inhibitor protein CD46 was seen in stomach > kidney > skeletal muscle, with similar expression in $\mathrm{CD} 59^{+/+}$and $\mathrm{CD}_{59^{-/-}}$rats. Relatively little CD55 was seen in these peripheral organs.
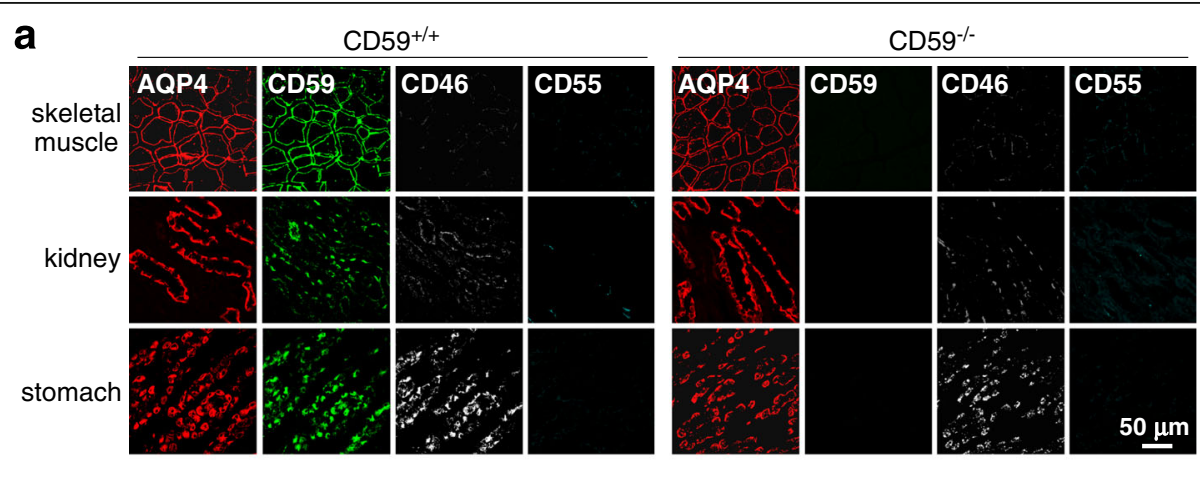

b

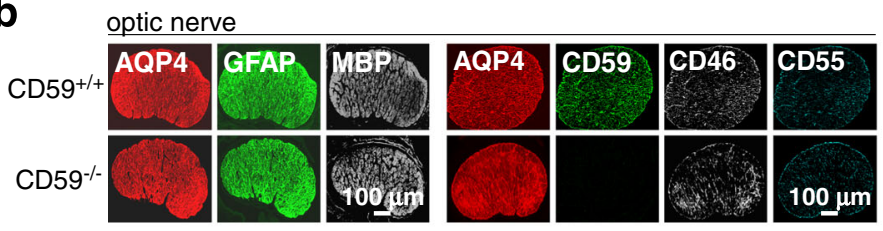

C spinal cord
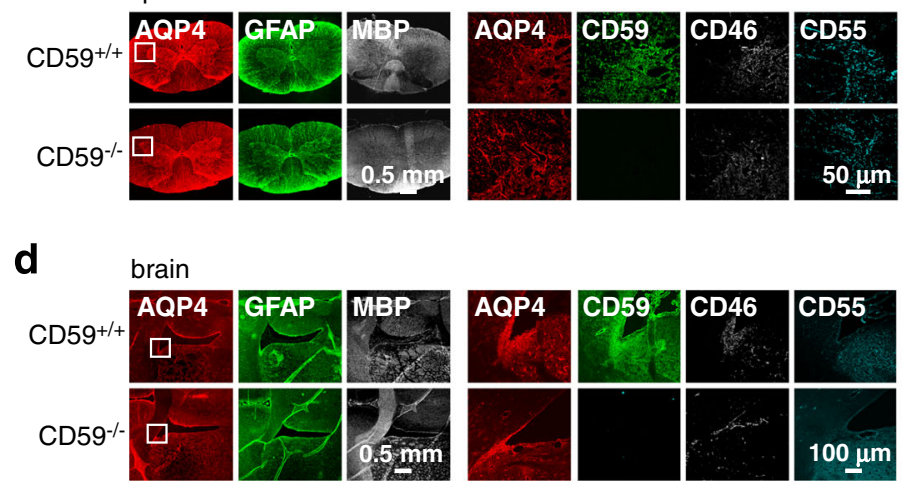

Fig. 1 Expression of AQP4 and complement regulator proteins CD59, CD55, and CD46 in peripheral organs and central nervous system. Immunofluorescence in skeletal muscle, kidney and stomach (a), optic nerve (b), spinal cord (c), and brain (in circumventricular region) (d). Micrographs in $\mathrm{c}$ and $\mathrm{d}$ shown at low and high (boxed region) magnifications. Representative of studies done in 3 rats per genotype 
Immunofluorescence in optic nerve, spinal cord and brain showed gross colocalization of astrocyte markers AQP4 and GFAP, with a distinct pattern of myelin (MBP) expression (Fig. 1b-d, left 3 panels). AQP4 coexpression with CD59 was seen in the three CNS tissues, with strongest CD59 immunofluorescence in brain, with different levels of CD46 and CD55 seen in the various tissues (right 4 panels). AQP4 immunofluorescence did not differ significantly in tissues from $\mathrm{CD} 59^{+/+}$and $\mathrm{CD} 59^{-/-}$ rats (relative to 1.0 for $\mathrm{CD} 59^{+/+}$rats: $1.01 \pm 0.06$ (optic nerve); $0.97 \pm 0.04$ (spinal cord); $0.96 \pm 0.09$ (brain)). CD59 immunofluorescence was absent in CNS tissues from $\mathrm{CD}^{-/-}$rats, and CD46 and CD55 immunofluorescence was similar in $\mathrm{CD} 59^{+/+}$and $\mathrm{CD} 59^{-/-}$rats.

\section{Marked weakness and serum $\mathrm{CK}$ elevation in $\mathrm{CD} 59^{-/-}$rats following systemic AQP4-lgG administration}

AQP4-IgG pharmacokinetics in $\mathrm{CD} 59^{+/+}$and $\mathrm{CD} 59^{-/-}$ rats was measured following a single intraperitoneal injection of AQP4-IgG. Human IgG concentration in rat serum was assayed by ELISA against human IgG, which does not detect rat IgG. Fig. 2a shows human IgG concentration in rat serum over $48 \mathrm{~h}$. AQP4-IgG concentration increased over the first few hours as it was absorbed from the peritoneal cavity, was maximum at $\sim 6 \mathrm{~h}$, and then decreased with $\mathrm{t}_{1 / 2} \sim 48 \mathrm{~h}$. Slightly lower AQP4-IgG concentrations were seen in $\mathrm{CD} 59^{-/-}$compared to $\mathrm{CD} 59^{+/+}$rats.

All AQP4-IgG-treated CD59 ${ }^{-/-}$rats developed marked weakness and motor disability at $24 \mathrm{~h}$, as exemplified in the short clip in Additional file 1 Video S1, with motor score data summarized in Fig. 2b. Little or no motor disability was seen in AQP4-IgG-treated $\mathrm{CD} 59^{+/+}$rats, in control (non-NMO) human IgG-treated $\mathrm{CD} 59^{+/+}$and $\mathrm{CD} 59^{-/-}$rats, and in AQP4-IgG-treated $\mathrm{CD} 59^{-/-}$rats administered a complement inhibitor just before and $12 \mathrm{~h}$ after AQP4-IgG administration. There was remarkable, >900-fold elevation in serum CK in the AQP4-IgG treated $\mathrm{CD} 59^{-/-}$rats, which was largely prevented by complement inhibition (Fig. 2c). Though there are several potential sources of $\mathrm{CK}$, the exceptionally high levels found in the treated rats are very likely to come from skeletal muscle.

Tables 1 and 2 summarize hematological parameters and chemistries of control and AQP4-IgG-treated rats. The data indicate a mild hemolytic anemia in untreated $\mathrm{CD} 59^{-1-}$ rats as evidenced by reduced hematocrit and mild reticulocytosis, as has been reported in humans lacking CD59 $[4,15]$. In AQP4-IgG-treated $\mathrm{CD} 59^{-/-}$ rats, in addition to the marked elevation in $\mathrm{CK}$, changes were seen in liver enzymes (AST and ALT) and kidney indices (BUN and creatinine), which is likely due to secondary effects of muscle injury, rhabdomyolysis and dehydration with reduced food intake. The treated CD59 ${ }^{-1-}$ rats also manifested a urinary concentrating defect (urine

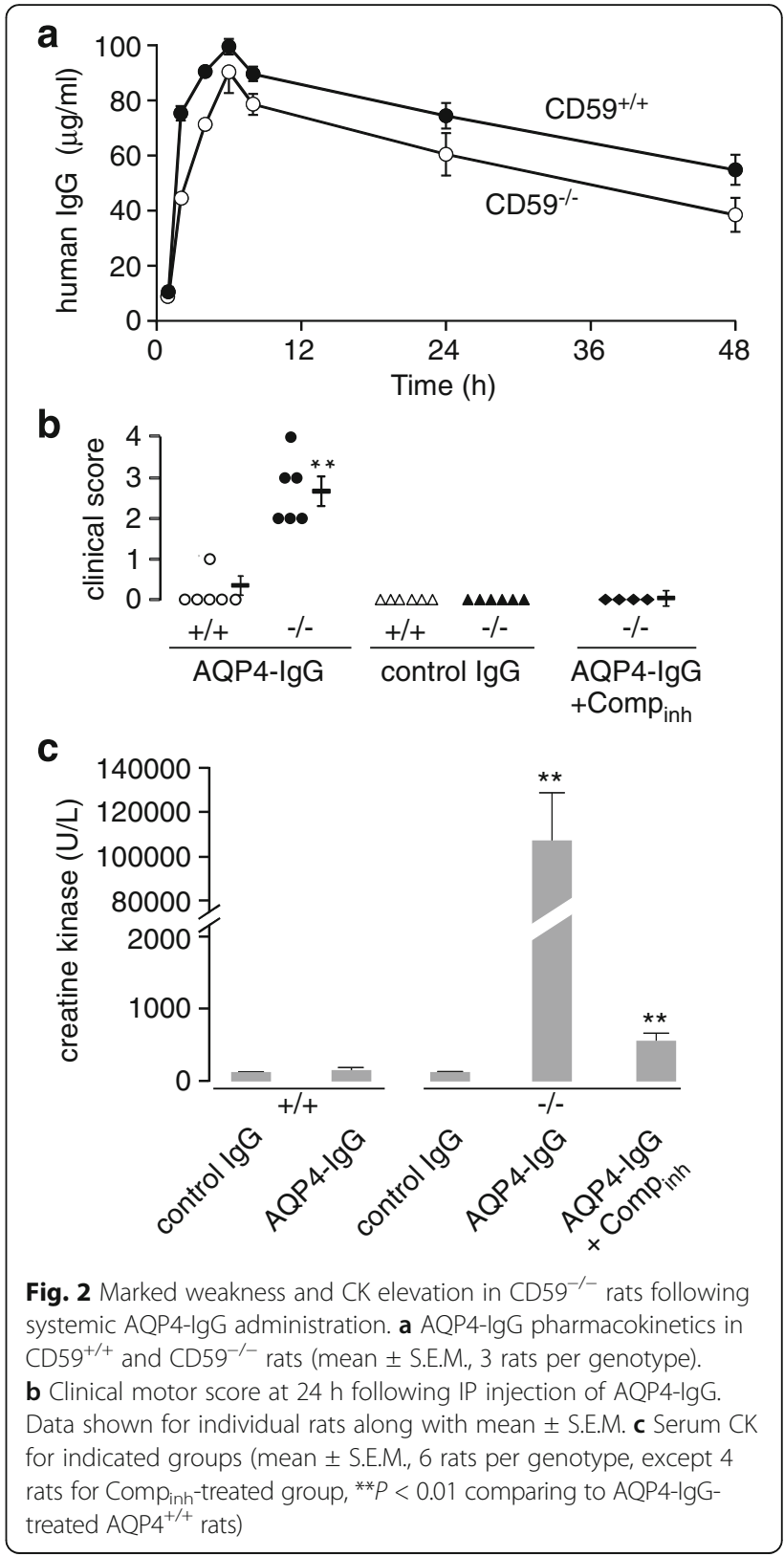

osmolality: AQP4-IgG-treated $521 \pm 96$ mOsm vs. control IgG-treated $1413 \pm 155 \mathrm{mOsm}$, S.E.M. 6 rats per group). The hemoconcentration in $\mathrm{CD} 59^{-/-}$rats is likely due to reduced fluid intake and dehydration.

\section{Pathology in peripheral, AQP4-expressing organs in AQP4-IgG seropositive $\mathrm{CD} 59^{-/-}$rats}

AQP4 and myosin-II immunofluorescence in hindlimb (tibialis anterior) muscle showed marked injury in AQP4-IgG treated CD59 ${ }^{-/-}$rats, with vacuole formation and disorganized myofibrils (Fig. 3a). Little or no abnormalities were seen in control (non-NMO) human IgG-treated $\mathrm{CD} 59^{+/+}$rats, AQP4-IgG-treated $\mathrm{CD} 59^{+/+}$rats, or complement inhibitor / AQP4-IgG-treated $\mathrm{CD} 59^{-/-}$rats. 
Table 1 Hematological parameters before and $24 \mathrm{~h}$ after IP injection of AQP4-lgG in CD59-/- and CD59+/+ rats

\begin{tabular}{|c|c|c|c|c|c|c|c|}
\hline & $\mathrm{Hb}(\mathrm{g} / \mathrm{dl})$ & RBC (1012/L) & $\mathrm{HCT}(\%)$ & RDW (\%) & Retic (\%) & WBC (109/L) & Plt $(109 / \mathrm{L})$ \\
\hline \multicolumn{8}{|c|}{ Before AQP4-lgG administration } \\
\hline $\mathrm{CD} 59^{+/+}$ & $15.1 \pm 2.0$ & $9.2 \pm 1.2$ & $44.4 \pm 6.0$ & $13.5 \pm 1.9$ & $0.0 \pm 0.0$ & $7.5 \pm 0.7$ & $870 \pm 162$ \\
\hline $\mathrm{CD} 59^{-/-}$ & $13.9 \pm 1.1$ & $8.5 \pm 0.9$ & $41.5 \pm 4.4$ & $13.4 \pm 1.0$ & $0.4 \pm 0.2^{+}$ & $8.1 \pm 1.4$ & $828 \pm 114$ \\
\hline \multicolumn{8}{|c|}{$24 \mathrm{~h}$ after AQP4-lgG administration } \\
\hline $\mathrm{CD} 59^{+/+}$ & $13.6 \pm 1.1$ & $8.8 \pm 0.9$ & $40.8 \pm 3.0$ & $13.3 \pm 1.9$ & $0.0 \pm 0.0$ & $6.8 \pm 3.4$ & $741 \pm 207$ \\
\hline $\mathrm{CD} 59^{-/-}$ & $18.4 \pm 1.8^{*}$ & $11.4 \pm 1.9^{*}$ & $55.7 \pm 6.1^{*}$ & $13.6 \pm 0.9$ & $0.3 \pm 0.1^{+}$ & $9.1 \pm 5.6$ & $685 \pm 195$ \\
\hline $\mathrm{CD}_{59^{-/-}}+$Comp $_{\mathrm{inh}}$ & $13.4 \pm 0.5$ & $7.6 \pm 0.2$ & $40.0 \pm 2.4$ & $12.6 \pm 0.7$ & $0.3 \pm 0.2^{+}$ & $5.2 \pm 1.2$ & $686 \pm 99$ \\
\hline
\end{tabular}

Mean \pm S.E.M. of 4-6 rats per genotype (three males and three females)

$H b$ hemoglobin, RBC red blood cell count, $H C T$ hematocrit, RDW RBC distribution width; Retic reticulocyte count, WBC white blood cell count, Plts platelet count

${ }^{*} p<0.01$ comparing with AQP4-IgG-treated CD59 ${ }^{+/+}$rats. ${ }^{+} p<0.01$ comparing with untreated $\operatorname{CD} 59^{+/+}$rats

AQP4 immunofluorescence showed a patchy expression pattern and was significantly reduced in skeletal muscle of AQP4-IgG-treated $\mathrm{CD} 59^{-/-}$rats, with quantitative data summarized in Fig. 3b. Similar pathology was seen in skeletal muscle from forelimb (triceps brachii), back (latissimus dorsi) and diaphragm (Fig. 3c). Fig. 3d shows deposition of activated complement (C5b-9) and inflammatory cell infiltration (CD45) in tibialis anterior muscle of AQP4-IgGtreated $\mathrm{CD} 59^{-/-}$rats. We did not stain for leukocyte subtypes. AQP4-IgG deposition (hIgG staining) was seen in the AQP4-IgG-treated $\mathrm{CD} 59^{+/+}$rats, but to a lesser extent in $\mathrm{CD} 59^{-1-}$ rats where AQP4 was largely gone. CD59 thus plays an important role in protection of skeletal muscle in seropositive NMO.

In kidney inner medulla where AQP4-expressing inner medullary collecting ducts are located, AQP4-IgG-treated rats showed loss of AQP4 immunofluorescence, as well as some deposition of activated complement and inflammatory cell infiltration, each of which were prevented by complement inhibition (Fig. 4a). Interestingly, in stomach, no significant changes in AQP4 expression were seen in AQP4-IgG-treated CD59 ${ }^{-/-}$rats, nor was there demonstrable deposition of activated complement or inflammatory cell infiltration (Fig. 4b).

Table 2 Blood chemistries before and $24 \mathrm{~h}$ after IP injection of AQP4-lgG in CD59 ${ }^{-/-}$and CD59 ${ }^{+/+}$rats

\begin{tabular}{|c|c|c|c|c|c|}
\hline Parameters & $\begin{array}{l}\mathrm{CD} 59^{+/+} \\
\text {before }\end{array}$ & $\begin{array}{l}\mathrm{CD}_{59} 9^{+/+} \\
\text {after }\end{array}$ & $\begin{array}{l}{\mathrm{CD} 59^{-/-}}^{-} \\
\text {before }\end{array}$ & $\begin{array}{l}\mathrm{CD}_{59} 9^{-/-} \\
\text {after }\end{array}$ & $\begin{array}{l}\mathrm{CD}_{59^{-/-}} \\
+ \text {Comp }_{\text {inh }}\end{array}$ \\
\hline $\mathrm{ALP}(\mathrm{U} / \mathrm{L})$ & $106 \pm 77$ & $63 \pm 60$ & $142 \pm 93$ & $117 \pm 89$ & $122 \pm 21$ \\
\hline AST (U/L) & $60 \pm 9$ & $81 \pm 23$ & $129 \pm 51$ & $5784 \pm 1021^{*}$ & $252 \pm 34^{*}$ \\
\hline ALT $(U / L)$ & $36 \pm 9$ & $30 \pm 9$ & $50 \pm 10$ & $1182 \pm 298^{*}$ & $60 \pm 14$ \\
\hline Creatine Kinase $(U / L)$ & $85 \pm 9$ & $120 \pm 51$ & $92 \pm 9$ & $106,767 \pm 42901^{*}$ & $547 \pm 84^{*}$ \\
\hline Albumin (g/dL) & $2.9 \pm 0.2$ & $2.9 \pm 0.3$ & $2.9 \pm 0.2$ & $2.9 \pm 0.3$ & $2.8 \pm 0.3$ \\
\hline Total Bilirubin (mg/dL) & $0.1 \pm 0.1$ & $0.1 \pm 0.0$ & $0.1 \pm 0.0$ & $0.2 \pm 0.1$ & $0.1 \pm 0.0$ \\
\hline Total Protein (g/dL) & $5.8 \pm 0.3$ & $6.1 \pm 0.3$ & $5.8 \pm 0.3$ & $6.7 \pm 0.6$ & $5.6 \pm 0.3$ \\
\hline Globulin (g/dL) & $2.9 \pm 0.4$ & $3.2 \pm 0.4$ & $2.9 \pm 0.2$ & $3.8 \pm 0.1$ & $2.8 \pm 0.1$ \\
\hline $\mathrm{BUN}(\mathrm{mg} / \mathrm{dL})$ & $13.6 \pm 2.9$ & $13.3 \pm 3.3$ & $14.7 \pm 1.3$ & $124 \pm 46^{*}$ & $16.0 \pm 4.4$ \\
\hline Creatinine $(\mathrm{mg} / \mathrm{dL})$ & $0.2 \pm 0.0$ & $0.3 \pm 0.1$ & $0.2 \pm 0.1$ & $1.2 \pm 0.8^{*}$ & $0.3 \pm 0.1$ \\
\hline Cholesterol (mg/dL) & $84 \pm 20$ & $83 \pm 21$ & $69 \pm 11$ & $110 \pm 25$ & $71 \pm 10$ \\
\hline Glucose (mg/dL) & $208 \pm 32$ & $183 \pm 14$ & $198 \pm 39$ & $148 \pm 82$ & $205 \pm 12$ \\
\hline Calcium (mg/dL) & $6.9 \pm 4.4$ & $5.1 \pm 4.9$ & $7.1 \pm 4.2$ & $6.2 \pm 3.9$ & $9.9 \pm 0.2$ \\
\hline Phosphorus (mg/dL) & $5.3 \pm 0.8$ & $6.1 \pm 1.1$ & $6.0 \pm 0.9$ & $16.7 \pm 6.1$ & $6.9 \pm 0.7$ \\
\hline Bicarbonate (mmol/L) & $20 \pm 4$ & $21 \pm 2$ & $21 \pm 2$ & $20 \pm 4$ & $22 \pm 2$ \\
\hline Chloride (mmol/L) & $99 \pm 4$ & $98 \pm 5$ & $100 \pm 3$ & $90 \pm 5$ & $105 \pm 3$ \\
\hline Sodium (mmol/L) & $136 \pm 8$ & $140 \pm 2$ & $138 \pm 5$ & $136 \pm 6$ & $143 \pm 3$ \\
\hline
\end{tabular}

Mean \pm S.E.M. of 4-6 rats per genotype (three males and three females)

$A L P$ alkaline phosphatase, AST/ALT aspartate aminotransferase/alanine aminotransferase, $C K$ creatine kinase, $B U N$ blood urea nitrogen

${ }^{*} p<0.01$ comparing with untreated $\mathrm{CD} 59^{-/-}$rats 

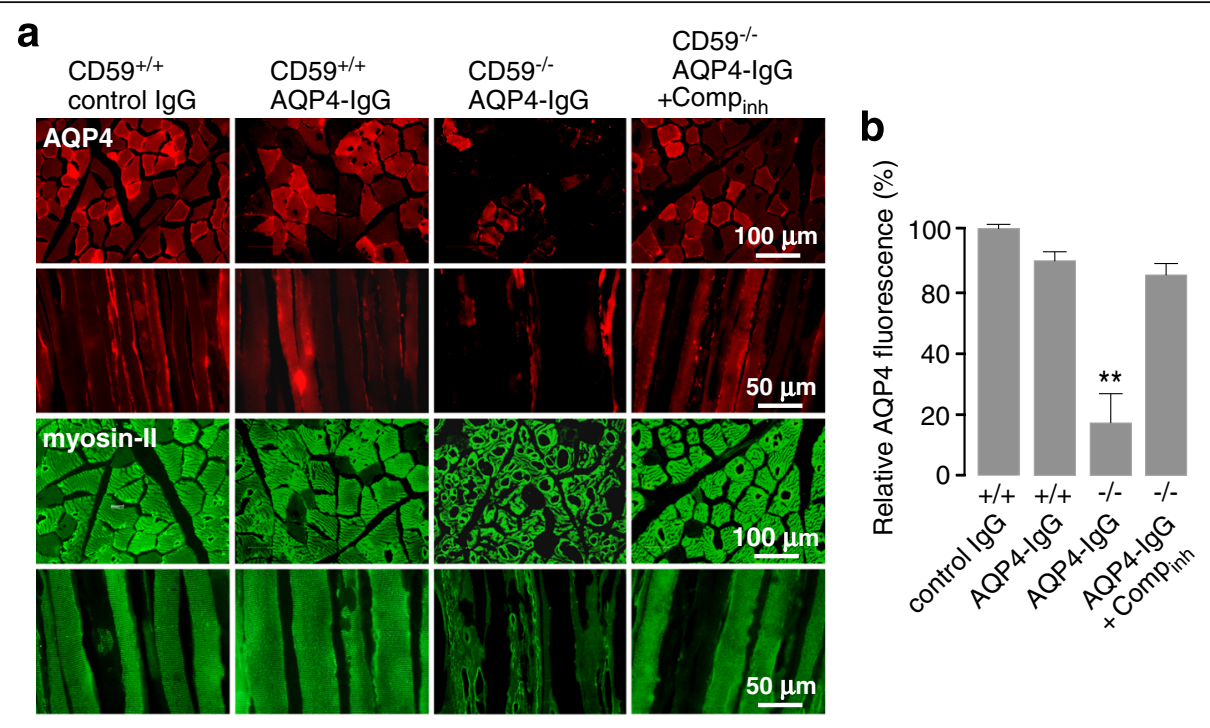

C
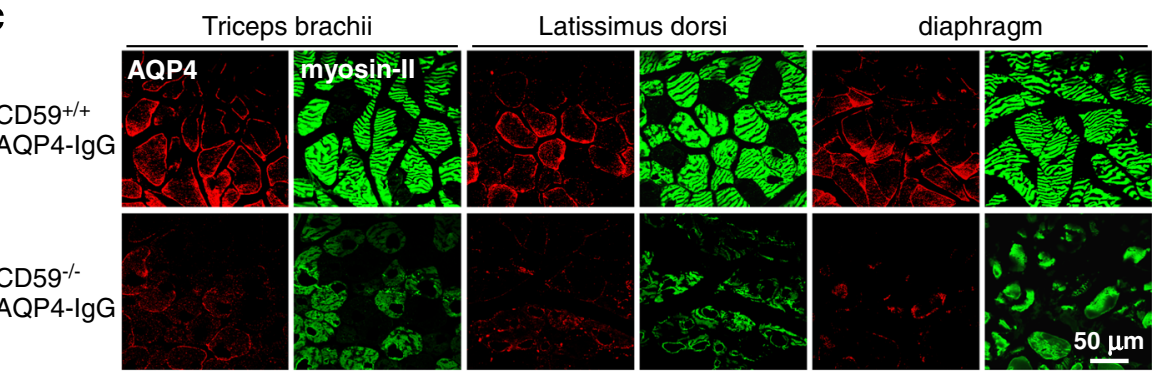

d

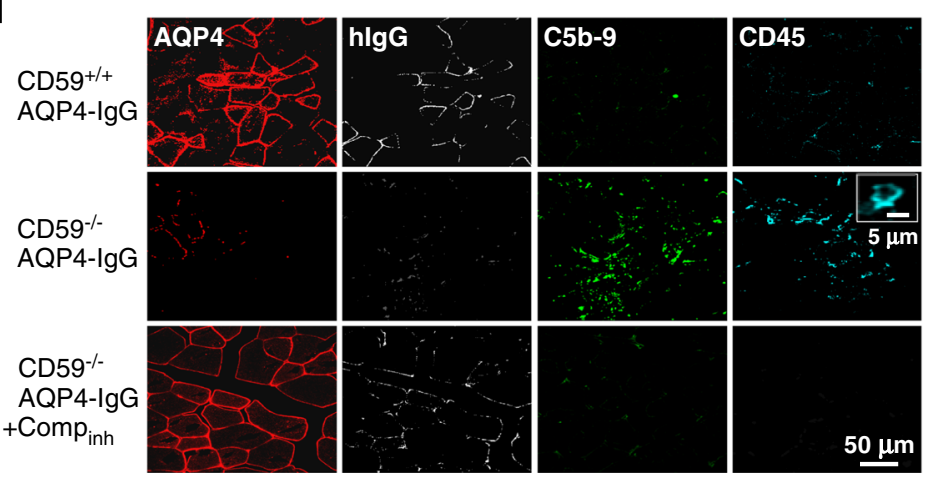

Fig. 3 Immunofluorescence in skeletal muscle at $24 \mathrm{~h}$ after intraperitoneal AQP4-lgG administration. a AQP4 and myosin-II immunofluorescence of tibialis anterior muscle, representative of $4-6$ rats per group. b Relative AQP4 immunofluorescence (mean \pm S.E.M., 4-6 rats per group, ${ }^{* *} P<0.01$ compared to control IgG group). c Immunofluorescence of front limb (triceps brachii), back (latissimus dorsi) and diaphragm muscle in AQP4-lgG-treated $\mathrm{CD}_{5} 9^{+/+}$and $\mathrm{CD} 59^{-/-}$rats as in panel a, representative of 3 rats. d AQP4, hlgG, C5b-9 and CD45 immunofluorescence in tibialis anterior muscle. Representative of 3 rats per group

Absence of pathology in the central nervous system of AQP4-IgG seropositive $\mathrm{CD}^{2} 9^{-/-}$rats

Examination of optic nerve (Fig. 5a), spinal cord (Fig. 5b) and circumventricular brain (Fig. 5c) did not show NMO pathology in AQP4-IgG-treated CD59 ${ }^{-/-}$rats. AQP4 expression was similar to that in control $\mathrm{CD} 59^{+/+}$rats, and neither complement deposition nor inflammation (CD45 and Iba-1) was seen. AQP4-IgG deposition (hIgG) was not seen in optic nerve or spinal cord, suggesting that AQP4IgG cannot access these tissues over the 24-h time. hIgG staining was, however, mildly positive in circumventricular brain tissue that lacks a tight blood-brain barrier.

\section{Discussion}

The principal finding here is that rats lacking complement inhibitor protein CD59 develop marked weakness 


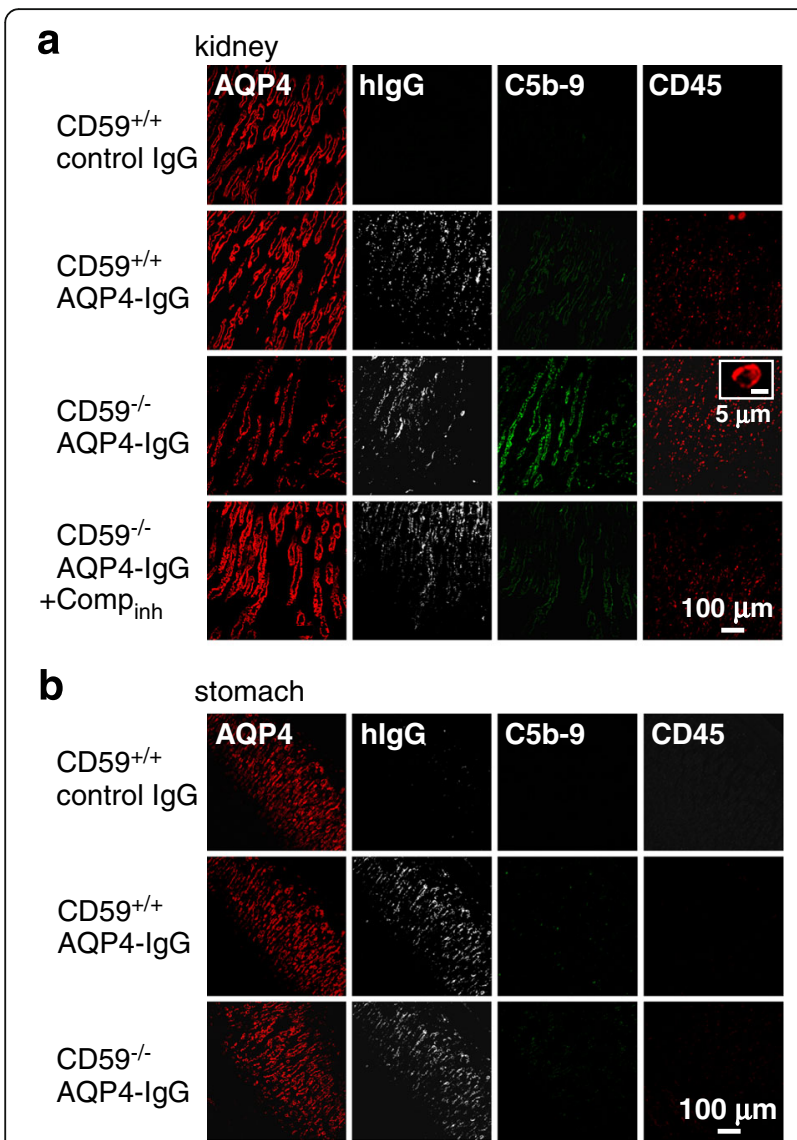

Fig. 4 Immunofluorescence in kidney and stomach at $24 \mathrm{~h}$ after intraperitoneal AQP4-lgG administration. AQP4, hlgG, C5b-9 and CD45 immunofluorescence in kidney (a) and stomach (b). Representative of 3 rats per group

and pathological changes in AQP4-expressing skeletal muscle following systemic administration of AQP4-IgG, whereas under identical conditions wildtype rats do not. Mild pathological changes were also seen in AQP4expressing epithelial cells in the renal inner medullary collecting duct, but not in AQP4-expressing gastric parietal cells. Injured AQP4-expressing cells in skeletal muscle of $\mathrm{CD} 9^{-/-}$rats showed reduced AQP4 expression, deposition of activated complement, and inflammation. Skeletal muscle injury was associated with marked elevation in serum creatine phosphokinase, which was largely prevented by complement inhibition, supporting the conclusion that complement-dependent cytotoxicity is responsible for peripheral organ injury in the seropositive $\mathrm{CD} 59^{-1-}$ rats. The absence of demonstrable brain or spinal cord injury suggests that the marked motor dysfunction seen by $24 \mathrm{~h}$ is the consequence of acute skeletal muscle injury rather than central nervous system injury. Respiratory failure because of diaphragmatic involvement may have contributed to the early mortality. The study here required $\mathrm{CD} 59^{-/-}$rats rather than mice because of the low activity of mouse complement, precluding the use of mice to study the consequences of systemic AQP4-IgG seropositivity.

There are a few reports of NMO myositis with elevated serum $\mathrm{CK}$, though no reports of $\mathrm{NMO}$-associated pathology in other AQP4-expressing peripheral organs. In a report of 2 seropositive NMO patients with diffuse myalgias, a substantial transient elevation of CK was found, with muscle biopsy showing reduced AQP4 expression and deposition of activated complement [13], similar to the pathological changes seen in seropositive

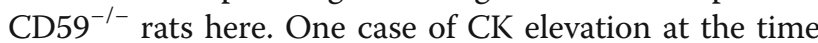
of NMO attacks was reported, but without muscle findings [7]. In a retrospective study of 733 cases of NMO in Japan, three patients were found with CK elevation and general fatigue weeks before symptoms of optic neuritis [27]. Though renal disease has not been reported in NMO, perhaps some patients manifest a mild urinary concentrating defect, as found in AQP4 knockout mice [12], and perhaps urinalysis might reveal cellular evidence of collecting duct injury.

Our findings support the conclusion that peripheral organ injury is largely absent in seropositive NMO because of protection by CD59 against complementmediated injury in AQP4-expressing cells. Perhaps the myositis seen in a very small number of NMO patients is caused by altered CD59 expression or CD59 polymorphisms, though this possibility has not been investigated. It would also be interesting to study the expression of CD59 and other complement regulator proteins in central nervous system and peripheral organ in human NMO. The apparent greater sensitivity of skeletal muscle to complement-induced injury, compared with other AQP4-expressing peripheral organs, might be related to the greater metabolic activity of skeletal muscle cells, or perhaps to differences in the expression of other complement inhibitors. Our results also support the central role of CD59 in the modulation of AQP4-IgG-initiated complement injury and hence suggest the potential therapeutic benefit in NMO of upregulation of astrocyte CD59 or alternative complement regulator proteins by pharmacological or other means.

Previously, various explanations have been offered for the general absence of NMO disease in peripheral, AQP4-expressing organs. Once set of explanations focus on AQP4, postulating that differences in AQP4 expression, localization or membrane clustering affect AQP4IgG binding and consequent complement activation $[14,25]$. However, the robust binding of AQP4-IgG to peripheral AQP4-expressing cells in rodents argues strongly against an AQP4-centric explanation, as do AQP4 biochemical and freeze-fracture electron microscopy studies $[19,23,30,31]$. AQP4-IgG is deposited in skeletal muscle where it has been studied in seropositive humans 


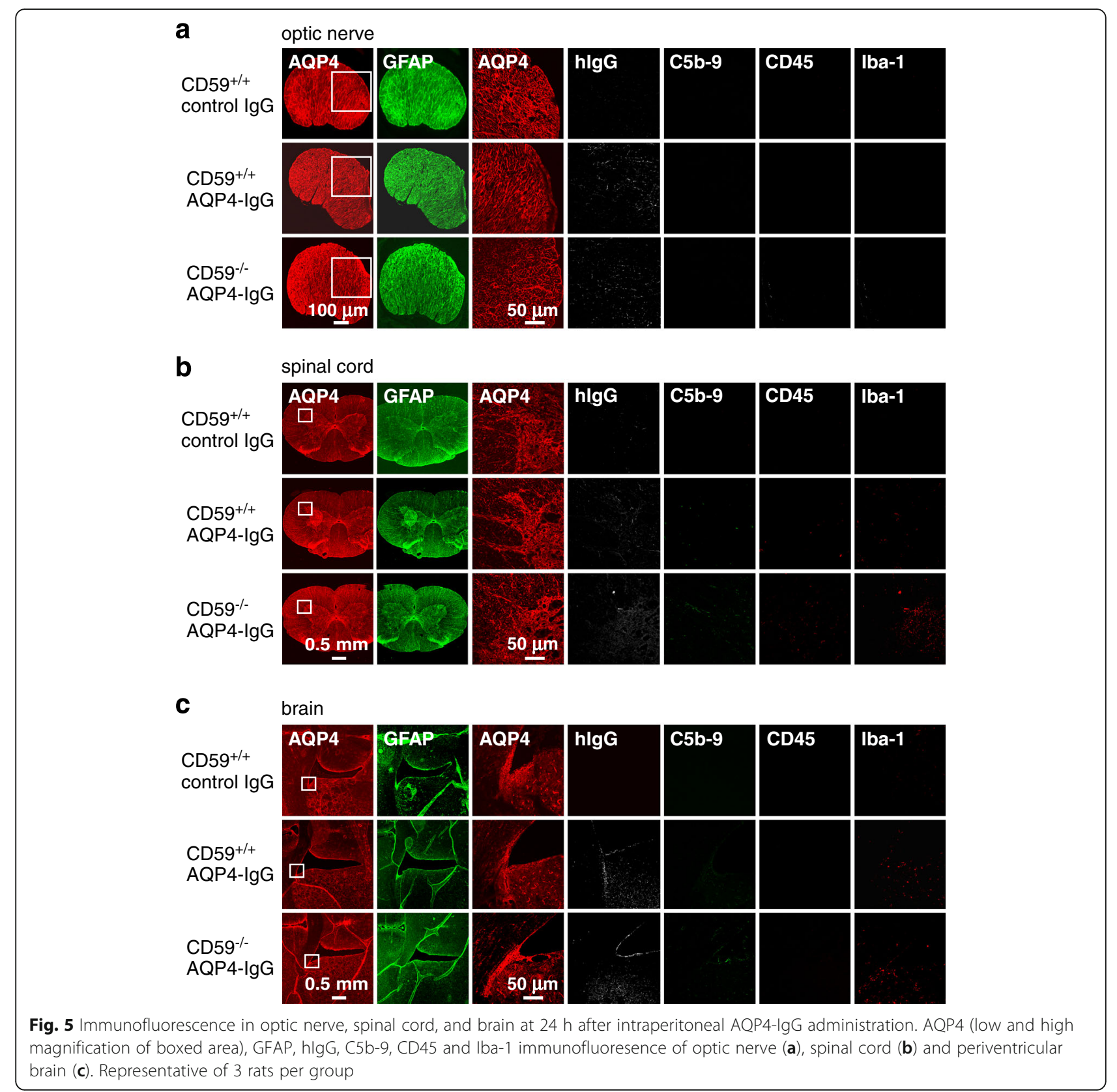

[13], and AQP4-IgG is rapidly deposited in multiple AQP4-expressing peripheral organs following its systemic delivery to rodents $[1,20]$. Another possible explanation for sparing of peripheral organs in NMO is the unique milieu of the central nervous system, which, unlike peripheral organs, might amplify an inflammatory response because of the presence of microglia, a narrow extracellular space, and a blood-brain barrier that impedes inflammatory cell exit. However, there is no experimental evidence to support this explanation.

The findings here raise the question of why CD59 in astrocytes does not fully protect against AQP4-IgG/complement injury as it appears to do in peripheral organs. Our prior data using mouse and rat models of NMO produced by injection of AQP4-IgG into brain or the spinal cerebrospinal space implicate a protective role for CD59 in brain and spinal cord in vivo [32, 33], which was supported by in vitro data in astrocyte cultures from knockout mice and rats or following CD59 enzymatic neutralization. Saadoun and Papadopoulos [24] reported that complement inhibitors, including CD59, are not protective against complement injury in CNS tissues. Though this conclusion is not supported by our findings in $\mathrm{CD} 59^{-/-}$rats and mice, they reported interesting immunofluorescence in mouse brain in which CD59 expression was seen on astrocyte cell bodies but not on AQP4-rich foot-processes near microvessels. 
We believe that higher-resolution imaging studies using electron microscopy or super-resolution fluorescence microscopy are needed to resolve unambiguously the subcellular localization of CD59 and AQP4 in brain sections. With regard to why CD59 is not fully protective against AQP4-IgG injury in the central nervous system, perhaps, as mentioned above, the unique cellular and physical milieu in brain, spinal cord and optic nerve, such as the presence of microglia and a narrow extracellular space, might amplify subthreshold AQP4-IgG-induced injury. We recently reported evidence for complement bystander injury to oligodendrocytes, which lack CD59, following exposure of nearby astrocytes to AQP4-IgG and complement [28]. While bystander cytotoxicity may be a major mechanism of cellular injury in the central nervous system, it may be inconsequential in peripheral AQP4-expressing organs.

Lastly, we acknowledge limitations in extrapolating the conclusions here from studies done in $\mathrm{CD} 59^{-/-}$rats to human NMO. Though the major anatomical structures are similar in rats and humans, there are differences in the ratios of various cell types in the central nervous system such as astrocytes and neurons, and there may be differences in expression levels of CD59 and other complement inhibitor proteins. Though there is compelling evidence for the pathogenicity of AQP4-IgG and complement, the passive-transfer model used here may not fully recapitulate the pathogenesis of seropositive NMO in humans, where additional mechanisms, perhaps cytotoxic $\mathrm{T}$ cells, might also contribute. Finally, the data here were from short-term follow-up after systemic AQP4-IgG administration to rats, which was necessitated by the severe pathology in AQP4-IgG-treated $\mathrm{CD} 59^{-/-}$rats. Peripheral organs in humans with seropositive NMO can be exposed to AQP4-IgG continuously for many years or decades. Notwithstanding these potential limitations, our results offer a logical explanation for the general absence of NMO disease outside of the central nervous system.

\section{Conclusions}

Our results provide evidence that CD59 expression in peripheral, AQP4-expressing organs is responsible for the absence of peripheral organ injury in seropositive NMO.

\section{Additional file}

Additional file 1: Video S1. $\mathrm{AQP4}^{+/+}$rat (right) and $\mathrm{AQP4}{ }^{-/-}$rat (left) at $24 \mathrm{~h}$ after intraperitoneal AQP4-IgG administration. (MOV $2356 \mathrm{~kb}$ )

\section{Acknowledgments}

This work was supported by grants EY13574, EB00415, DK35124, and DK72517 from the National Institutes of Health, and a grant from the Guthy-Jackson Charitable Foundation. We thank Dr. Jeffrey Bennett (Univ. Colorado Denver, Aurora, $\mathrm{CO}$ ) for providing recombinant monoclonal NMO antibodies.

\section{Authors' contributions}

$X Y$ and ASV conceived of the study, analyzed data, and wrote the manuscript. XY carried out experiments. Both authors read and approved the final manuscript.

\section{Competing interests}

The authors declare that they have no competing interest.

\section{Publisher's Note}

Springer Nature remains neutral with regard to jurisdictional claims in published maps and institutional affiliations.

Received: 22 July 2017 Accepted: 22 July 2017

Published online: 27 July 2017

\section{References}

1. Asavapanumas N, Verkman AS (2014) Neuromyelitis optica pathology in rats following intraperitoneal injection of $\mathrm{NMO}-\mathrm{IgG}$ and intracerebral needle injury. Acta Neuropathol Commun 2:48

2. Bennett JL, Lam C, Kalluri SR, Saikali P, Bautista K, Dupree C, Glogowska M, Case D, Antel JP, Owens GP, Gilden D, Nessler S, Stadelmann C, Hemmer B (2009) Intrathecal pathogenic anti-aquaporin-4 antibodies in early neuromyelitis optica. Ann Neurol 66:617-629

3. Bergman I, Basse PH, Barmada MA, Griffin JA, Cheung NK (2000) Comparison of in vitro antibody-targeted cytotoxicity using mouse, rat and human effectors. Cancer Immunol Immunother 49:259-266

4. Brodsky RA (2015) Complement in hemolytic anemia. Blood 126:2459-2465

5. Crane JM, Lam C, Rossi A, Gupta T, Bennett JL, Verkman AS (2011) Binding affinity and specificity of neuromyelitis optica autoantibodies to aquaporin-4 M1/M23 isoforms and orthogonal arrays. J Biol Chem 286:16516-16524

6. Davies A, Lachmann PJ (1993) Membrane defence against complement lysis: the structure and biological properties of CD59. Immunol Res 12:258-275

7. Deguchi S, Deguchi K, Sato K, Yunoki T, Omote Y, Morimoto N, Kurata T, Ikeda M, Takahashi T, Aoki M, Abe K (2012) HyperCKemia related to the initial and recurrent attacks of neuromyelitis optica. Intern Med 51:2617-2620

8. Frigeri A, Gropper MA, Umenishi F, Kawashima M, Brown D, Verkman AS (1995) Localization of MIWC and GLIP water channel homologs in neuromuscular, epithelial and glandular tissues. J Cell Sci 108:2993-3002

9. Hinson SR, Lennon VA, Pittock SJ (2016) Autoimmune AQP4 channelopathies and neuromyelitis optica spectrum disorders. Handb Clin Neurol 133:377-403

10. Iwamoto N, Kawaguchi T, Nagakura S, Hidaka M, Horikawa K, Kagimoto T, Takatsuki K, Nakakuma H (1995) Markedly high population of affected reticulocytes negative for decay-accelerating factor and CD59 in paroxysmal nocturnal hemoglobinuria. Blood 85:2228-2232

11. Jarius S, Wildemann B, Paul F (2014) Neuromyelitis optica: clinical features, immunopathogenesis and treatment. Clin Exp Immunol 176:149-164

12. Levy M, Wildemann B, Jarius S, Orellano B, Sasidharan S, Weber MS, Stuve O (2014) Immunopathogenesis of neuromyelitis optica. Adv Immunol 121:213-242

13. Ma T, Yang B, Gillespie A, Carlson EJ, Epstein CJ, Verkman AS (1997) Generation and phenotype of a transgenic knockout mouse lacking the mercurial-insensitive water channel aquaporin-4. J Clin Invest 100:957-962

14. Malik R, Lewis A, Cree BA, Ratelade J, Rossi A, Verkman AS, Bollen AW, Ralph JW (2014) Transient hyperckemia in the setting of neuromyelitis optica (NMO). Muscle Nerve 50:859-862

15. Matiello M, Schaefer-Klein J, Sun D, Weinshenker BG (2013) Aquaporin 4 expression and tissue susceptibility to neuromyelitis optica. JAMA Neurol 70:1118-1125

16. Nevo $Y$, Ben-Zeev B, Tabib A, Straussberg R, Anikster $Y$, Shorer Z, FattalValevski A, Ta-Shma A, Aharoni S, Rabie M, Zenvirt S, Goldshmidt H, Fellig Y, Shaag A, Mevorach D, Elpeleg O (2013) CD59 deficiency is associated with chronic hemolysis and childhood relapsing immune-mediated polyneuropathy. Blood 121:129-135

17. Nishiyama S, Ito T, Misu T, Takahashi T, Kikuchi A, Suzuki N, Jin K, Aoki M, Fujihara K, Itoyama Y (2009) A case of NMO seropositive for aquaporin-4 antibody more than 10 years before onset. Neurology 72:1960-1961

18. Papadopoulos MC, Verkman AS (2013) Aquaporin water channels in the nervous system. Nat Rev Neurosci 14:265-277

19. Papadopoulos MC, Bennett JL, Verkman AS (2014) Treatment of neuromyelitis optica: state-of-the-art and emerging therapies. Nat Rev Neurol 10:493-506

20. Perez-Nievas BG, Garcia-Bueno B, Madrigal JL, Leza JC (2010) Chronic immobilisation stress ameliorates clinical score and neuroinflammation in a MOG-induced EAE in dark agouti rats: mechanisms implicated. J Neuroinflamm 7:60 
21. Ratelade J, Verkman AS (2014) Inhibitor(s) of the classical complement pathway in mouse serum limit the utility of mice as experimental models of neuromyelitis optica. Mol Immunol 62:104-113

22. Ratelade J, Bennett JL, Verkman AS (2011) Intravenous neuromyelitis optica autoantibody in mice targets aquaporin-4 in peripheral organs and area postrema. PLoS One 6:e27412

23. Rossi A, Ratelade J, Papadopoulos MC, Bennett JL, Verkman AS (2010) Neuromyelitis optica lgG does not alter aquaporin-4 water permeability, plasma membrane M1/M23 isoform content, or supramolecular assembly. Glia 60:2027-2039

24. Saadoun S, Papadopoulos MC (2015) Role of membrane complement regulators in neuromyelitis optica. Mult Scler 21:1644-1654

25. Saini H, Fernandez G, Kerr D, Levy M (2010) Differential expression of aquaporin-4 isoforms localizes with neuromyelitis optica disease activity. J Neuroimmunol 221:68-72

26. Schmidt CQ, Lambris JD, Ricklin D (2016) Protection of host cells by complement regulators. Immunol Rev 274:152-171

27. Suzuki N, Takahashi T, Aoki M, Misu T, Konohana S, Okumura T, Takahashi H, Kameya S, Yamaki K, Kumagai T, Fujihara K, Itoyama Y (2010) Neuromyelitis optica preceded by hyperCKemia episode. Neurology 74:1543-1545

28. Tradtrantip L, Yao X, Su T, Smith AJ, Verkman AS (2017) Bystander mechanism for complement-initiated early oligodendrocyte injury in neuromyelitis optica. Acta Neuropathol 134:35-44

29. Vaknin-Dembinsky A, Karussis D, Avichzer J, Abramsky O (2014) NMO spectrum of disorders: a paradigm for astrocyte-targeting autoimmunity and its implications for MS and other CNS inflammatory diseases. J Autoimmun 54:93-99

30. Verbavatz JM, Ma T, Gobin R, Verkman AS (1997) Absence of orthogonal arrays in kidney, brain and muscle from transgenic knockout mice lacking water channel aquaporin-4. J Cell Sci 110:2855-2860

31. Wakayama Y (2010) Aquaporin expression in normal and pathological skeletal muscles: a brief review with focus on AQP4. J Biomed Biotechnol 2010:731569

32. Yao X, Verkman AS (2017) Marked central nervous system pathology in CD59 knockout rats following passive transfer of Neuromyelitis optica immunoglobulin G. Acta Neuropathol Commun 5:15

33. Zhang H, Verkman AS (2014) Longitudinally extensive NMO spinal cord pathology produced by passive transfer of NMO-IgG in mice lacking complement inhibitor CD59. J Autoimmun 53:67-77

34. Zipfel PF, Skerka C (2009) Complement regulators and inhibitory proteins. Nat Rev Immunol 9:729-740

\section{Submit your next manuscript to BioMed Central and we will help you at every step:}

- We accept pre-submission inquiries

- Our selector tool helps you to find the most relevant journal

- We provide round the clock customer support

- Convenient online submission

- Thorough peer review

- Inclusion in PubMed and all major indexing services

- Maximum visibility for your research

Submit your manuscript at www.biomedcentral.com/submit

) Biomed Central 